\section{New Bird Records and Bird Diversity of Poyang Lake National Nature Reserve, Jiangxi Province, China}

\author{
Nanjing Zeng1, Guanhua Liu', Sibiao Wen ${ }^{1}$ and Feiyun Tu ${ }^{2, *}$ \\ ${ }^{1}$ Jiangxi Poyang Lake National Nature Reserve, Nanchang 330038, China \\ 2 Jiangxi Academy of Forestry, Nanchang 330013, China
}

\begin{abstract}
A B S T R A C T
Poyang Lake is an important overwintering site for migratory birds in Asia. Poyang Lake National Nature Reserve (PLNNR) is a hot spot for birds inhabiting or overwintering at Poyang Lake. Hitherto, limited checklist of bird species has been available. In order to investigate the bird diversity and avifauna of PLNNR, complete species checklist was strictly checked according to systematic analyses of species records from multisource. Fifty-seven species were newly recorded based on the previous study of 330 bird species. Six previously reported species were removed. We finally recorded 381 bird species, belonging to 18 orders 64 families, accounting for $27.8 \%$ of bird species in China; 205 species $(53.8 \%)$ are Palearctic, 83 (21.78\%) Oriental and the rest $93(24.42 \%)$ are cosmopolitan. Ten species are listed in grade I national key protected animals, and 56 species are designated in grade II national key protected animals. Four species (Bambusicola thoracicus, Turdus mupinensis, Garrulax poecilorhynchus and Parus venustulus) are endemic to China. Breeding birds account for 201 species (52.8\%) of the nature reserve bird species; 53 belong to Palearctic, 78 to Oriental Realms and the rest 70 cosmopolitan. The Oriental Realms species are dominated and the results are in accordance with features of Jiangxi avifauna. The G-F index of birds of PLNNR is 0.873 , higher than other nature reserves in Jiangxi Province. The study will contribute to the management and conservation of birds in PLNNR.
\end{abstract}
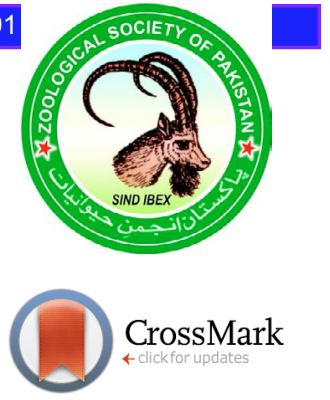

\section{INTRODUCTION}

$\mathrm{P}$ oyang Lake is the largest freshwater lake in China and the largest overwintering ground for migratory birds in Asia, with about 350,000 migratory birds belonging to 105 species in every winter ( $\mathrm{Hu}$ et al., 2014). It is also the most important wintering ground for the globally critically endangered Siberian crane Grus leucogeranus. In most years, more than 3000 Siberian cranes have overwintered in Poyang Lake, which has been defined as one of 35 priority protected areas in China by the Chinese government. The bird species diversity of Poyang Lake has been investigated by many researchers (Shan, 2013; Shao et al., 2013; Zeng et al., 2016a). Poyang Lake National Nature Reserve (PLNNR) has been designated as wetland of international importance. Since PLNNR was established in 1983, numerous bird surveys and monitoring have been conducted (Ji et al., 2001; Wu and Ji, 2002; Zhu et al., 2012; Chen et al., 2014; Zeng et al., 2016b). Many scholars and experts have carried out scientific surveys and research, and bird-lovers visited the protected area for

\footnotetext{
Corresponding author: feiyuntu@163.com 0030-9923/2018/0004-1285 \$9.00/0

Copyright 2018 Zoological Society of Pakistan
}

bird-watching or photography. Early bird watching records were not collected and sorted in time and it is extremely difficult to dig out the observation records thus only 330 bird species were recorded (Zeng et al., 2016b). Complete species checklist records are essential to understand regional bird diversity, the status of bird distribution and the start of conservation especially for endangered or rare bird species (Chen et al., 2012; Tu et al., 2016). However, comprehensive and systematic analyses of bird fauna and diversity in PLNNR remains largely unknown, and an updated species checklist awaits revision for conservation. Therefore, we analyzed avifauna and species diversity based on the updated species checklist which originally recorded 330 bird species (Zeng et al., 2016b), and several bird watching records from investigators by strict screening. The study aims to provide primary data for bird protection, management and scientific studies in PLNNR.

\section{MATERIALS AND METHODS}

\section{Natural conditions of study sites}

PLNNR $\quad\left(29^{\circ} 05^{\prime} \sim 29^{\circ} 15^{\prime} \mathrm{N} \quad 115^{\circ} 55^{\prime} \sim 116^{\circ} 03^{\prime} \mathrm{E}\right.$; $22,400 \mathrm{ha}$; elevation ranging from 14 to 17 meters) is located in the northwest of Poyang Lake. The PLNNR is comprised of nine lakes (Dahuchi, Banghu, Dachahu, 
Shahu, Zhonghuchi, Changhuchi, Meixihu, Xianghu and Zhushihu) of various sizes (Fig. 1). The Ganjiang and Xiuhe Rivers merge into Poyang Lake at Wucheng, a small township on the western side of the lake, also regarded as the center of PLNNR. The Poyang Lake is fed by Five Rivers (Ganjiang, Fuhe, Xinjiang, Raohe and Xiuhe) and Yangtze River. Thus, the lake turns into a vast expanse of water during floods but in the dry season it only remains a few belt-like waters. The cross-section height of typical wetlands in PLNNR ranges from 13 to 18 meters, and the ground slopes are mostly below $0^{\circ} 17^{\prime} 42^{\prime \prime}$, with very flat terrain. In the landscape, wetlands are comprised of natural barriers, lateral slopes and plate low-lying lands, which disperse in either side of branches of the watercourse. The structure of sedimentary section, ground elevation from high to low shows grass lands, sparse grass lands or mudflat, and water lowlands. The deposit sediments mainly contain fine silt, very fine silt and clay.

Multisource secondary data included: (1) bird banding records; (2) unpublished internal materials; (3) bird records in the website of China Bird Report Center
(CBRC) (http://www.birdreport.cn/index) provided by bird-lovers.

Complete species checklist was collected and added based on a recently reported list of 330 bird species (Zeng et al., 2016b). The earliest sources of literature were noted, new recorded species were screened and examined strictly, and the time and localities of several new recorded species were provided.

The species endangered status was revised by referring to the IUCN Red List of Threatened Species 2017 (http:// www.iucnredlist.org/). Species appendix information was examined following the CITES version provided by website of China's Endangered Species Scientific Commission, P.R. China (http://www.cites.org.cn/article/ list.php?catid=20). Classification of bird species, residents and Chinese endemic birds were checked as per Zheng (2011). The fauna reported by Hang and Chang (1997) was also referred. Indices of F, G and G-F were also calculated according to Jiang and Ji (1999) and compared the results with other national nature reserves in Jiangxi province (Huang et al., 2016).

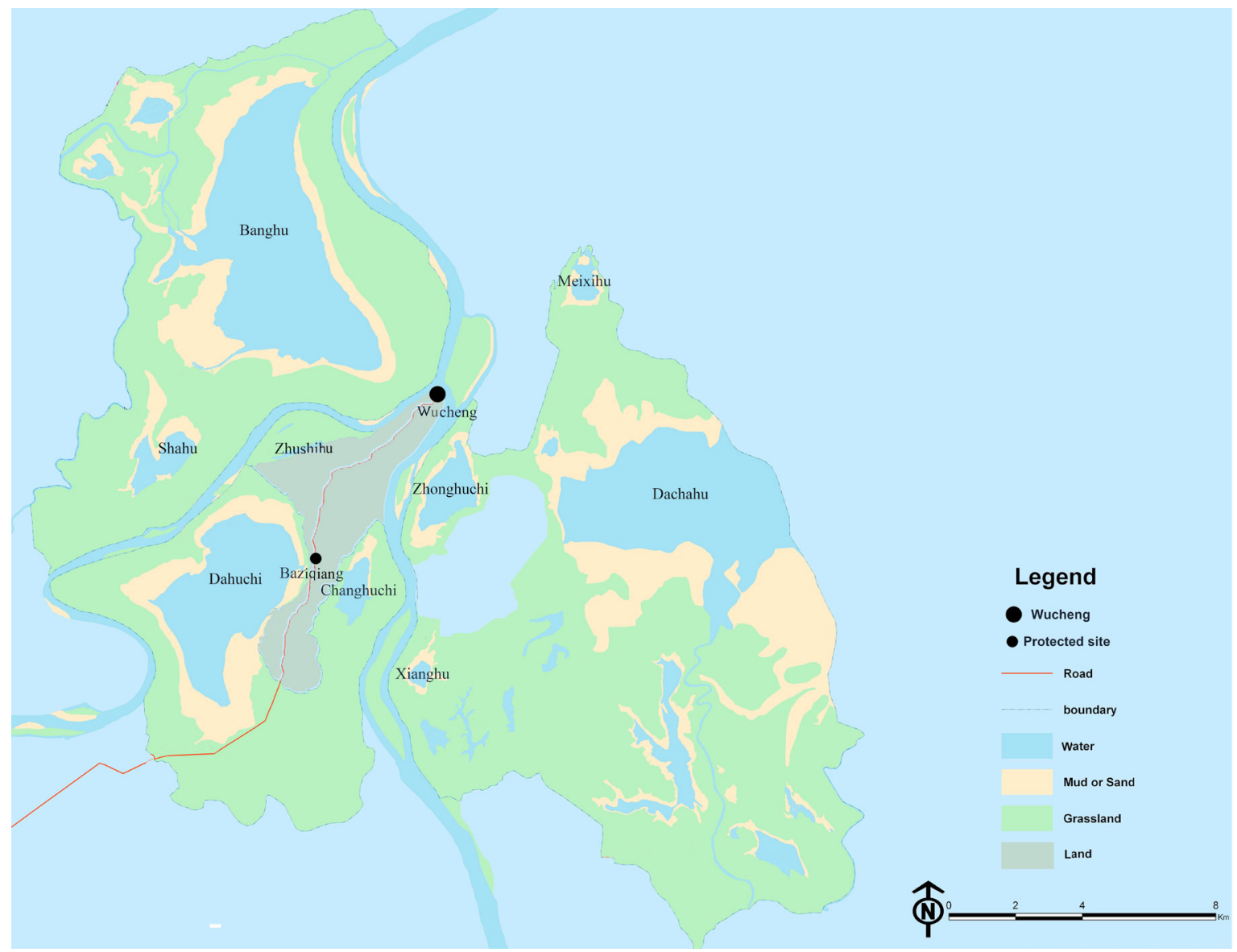

Fig. 1. Map of Poyang Lake National Nature Reserve, Jiangxi Province, China. 
Table I.- Checklist of new bird records at Poyang Lake National Nature Reserve.

\begin{tabular}{|c|c|c|c|c|c|c|}
\hline Scientific name & $\mathbf{R} / \mathbf{S} / \mathbf{W} / \mathbf{P}$ & Fauna & Protection level & IUCN & Source & Record time/ location \\
\hline Podiceps nigricollis & $\mathrm{P}$ & $\mathrm{P}$ & & $\mathrm{LC}$ & CBRC & 2008-12-06/Shahu \\
\hline Phoenicopterus ruber & V & $\mathrm{W}$ & & $\mathrm{LC}$ & CBRC & 2015-11/24/Dahuchi \\
\hline Aythya nyroca & $\mathrm{P}, \mathrm{W}$ & $\mathrm{P}$ & & NT & CBRC & 2012-12-15/Dachahu \\
\hline Bucephala clangula & W & $\mathrm{P}$ & & $\mathrm{LC}$ & Howes et al., 1988 & \\
\hline Pernis ptilorhynchus & $\mathrm{P}$ & $\mathrm{W}$ & II & $\mathrm{LC}$ & CBRC & 2016-2-9/Wucheng \\
\hline Spilornis cheela & $\mathrm{R}$ & $\mathrm{O}$ & II & $\mathrm{LC}$ & $\mathrm{CBRC}$ & 2013-12-1/Dahuchi \\
\hline Accipiter soloensis & $\mathrm{R}$ & $\mathrm{O}$ & II & $\mathrm{LC}$ & Liu, unpublished & \\
\hline Accipiter gularis & W,P & W & II & $\mathrm{LC}$ & CBRC & 2015-4-25/Baziqiang \\
\hline Accipiter virgatus & $\mathrm{R}$ & W & II & $\mathrm{LC}$ & CBRC & 2017-1-16 17/Wucheng \\
\hline Butastur indicus & & & II & & Liu, unpublished & \\
\hline Buteo lagopus & W & $\mathrm{P}$ & II & $\mathrm{LC}$ & Liu, unpublished & \\
\hline Ictinaetus malayensis & $\mathrm{R}$ & $\mathrm{O}$ & II & $\mathrm{LC}$ & CBRC & 2017-1-16 17/Wucheng \\
\hline Hieraaetus fasciata & $\mathrm{R}$ & $\mathrm{W}$ & II & $\mathrm{LC}$ & CBRC & 2015-12-19/Wucheng \\
\hline Francolinus pintadeanus & $\mathrm{R}$ & $\mathrm{O}$ & $\mathrm{P}$ & $\mathrm{LC}$ & Liu, unpublished & \\
\hline Pucrasia macrolopha & $\mathrm{R}$ & $\mathrm{W}$ & II & $\mathrm{LC}$ & Liu, unpublished & \\
\hline Lophura nycthemera & $\mathrm{R}$ & $\mathrm{O}$ & II & $\mathrm{LC}$ & Liu, unpublished & \\
\hline Grus japonensis & $\mathrm{W}$ & $\mathrm{P}$ & I & $\mathrm{EN}$ & Liu, unpublished & \\
\hline Charadrius leschenaultii & $\mathrm{P}$ & $\mathrm{P}$ & & $\mathrm{LC}$ & Howes et al., 1988 & \\
\hline Calidris ruficollis & $\mathrm{P}, \mathrm{W}$ & $\mathrm{P}$ & & NT & Howes et al., 1988 & \\
\hline Lymnocryptes minimus & $\mathrm{P}$ & $\mathrm{P}$ & & $\mathrm{LC}$ & Howes et al., 1988 & \\
\hline Calidris temminckii & $\mathrm{P}, \mathrm{W}$ & $\mathrm{P}$ & & $\mathrm{LC}$ & Howes et al., 1988 & \\
\hline Calidris minuta & & & & & Liu, unpublished & \\
\hline Larus fuscus heuglini & W & $\mathrm{P}$ & $\mathrm{P}$ & - & CBRC & 2011-1-14/Dahuchi \\
\hline Larus ichthyaetus & $\mathrm{V}$ & $\mathrm{P}$ & & $\mathrm{LC}$ & CBRC & 2016-12-3 4/Wucheng \\
\hline Riparia diluta & $\mathrm{S}$ & $P$ & $\mathrm{P}$ & - & $\mathrm{CBRC}$ & 2015-4-25/Baziqiang \\
\hline Motacilla citreola & W & $\mathrm{W}$ & & $\mathrm{LC}$ & CBRC & 2010-11-27/Wucheng \\
\hline Lanius tigrinus & S & $\mathrm{P}$ & $\mathrm{P}$ & $\mathrm{LC}$ & Liu, unpublished & \\
\hline Sturnus vulgaris & V & $\mathrm{P}$ & & $\mathrm{LC}$ & CBRC & 2010-12-29/Wucheng \\
\hline Dendrocitta formosae & $\mathrm{R}$ & $\mathrm{O}$ & & $\mathrm{LC}$ & Liu, unpublished & \\
\hline Brachypteryx montana & $\mathrm{R}$ & $\mathrm{O}$ & & $\mathrm{LC}$ & Liu, unpublished & \\
\hline Enicurus leschenaulti & $\mathrm{R}$ & $\mathrm{O}$ & & $\mathrm{LC}$ & CBRC & 2017-2-20 21/Wucheng \\
\hline Monticola solitarius & $\mathrm{R}$ & $\mathrm{W}$ & & $\mathrm{LC}$ & Liu, unpublished & \\
\hline Turdus naumanni & $\mathrm{W}, \mathrm{P}$ & $\mathrm{P}$ & & $\mathrm{LC}$ & CBRC & 2017-1-16 17/Wucheng \\
\hline Turdus mupinensis & $\mathrm{R}$ & $P$ & & $\mathrm{LC}$ & $\mathrm{CBRC}$ & 2012-11-23/Shahu \\
\hline Niltava davidi & S & $\mathrm{O}$ & & $\mathrm{LC}$ & Liu, unpublished & \\
\hline Culicicapa ceylonensis & $\mathrm{S}$ & $\mathrm{O}$ & & $\mathrm{LC}$ & Liu, unpublished & \\
\hline Garrulax pectoralis & $\mathrm{R}$ & $\mathrm{O}$ & & $\mathrm{LC}$ & Liu, unpublished & \\
\hline Garrulax cineraceus & $\mathrm{R}$ & $\mathrm{O}$ & & $\mathrm{LC}$ & Liu, unpublished & \\
\hline Garrulax poecilorhynchus & $\mathrm{R}$ & $\mathrm{O}$ & & $\mathrm{LC}$ & Liu, unpublished & \\
\hline Pomatorhinus erythrocnemis & $\mathrm{R}$ & $\mathrm{O}$ & & $\mathrm{LC}$ & Liu, unpublished & \\
\hline Stachyris ruficeps & $\mathrm{R}$ & $\mathrm{O}$ & & $\mathrm{LC}$ & Liu, unpublished & \\
\hline Leiothrix lutea & $\mathrm{R}$ & $\mathrm{O}$ & $\mathrm{P}$ & $\mathrm{LC}$ & Liu, unpublished & \\
\hline Alcippe morrisonia & $\mathrm{R}$ & $\mathrm{O}$ & & - & $\mathrm{CBRC}$ & 2013-10-04/Wucheng \\
\hline Paradoxornis gularis & $\mathrm{R}$ & $\mathrm{O}$ & & $\mathrm{LC}$ & Liu, unpublished & \\
\hline Cettia canturians & S & $\mathrm{W}$ & & - & CBRC & 2015-4-25/Baziqiang \\
\hline Cettia acanthizoides & $\mathrm{R}$ & $\mathrm{O}$ & & $\mathrm{LC}$ & $\mathrm{CBRC}$ & 2010-11-27/Wucheng \\
\hline Acrocephalus aedon & $P$ & $\mathrm{P}$ & & $\mathrm{LC}$ & $\mathrm{CBRC}$ & 2015-4-25/Baziqiang \\
\hline Phylloscopus plumbeitarsus & $\mathrm{P}$ & $\mathrm{P}$ & & - & CBRC & 2013-10-04/Wucheng \\
\hline
\end{tabular}




\begin{tabular}{lcccccc}
\hline Scientific name & R/S/W/P & Fauna & Protection level & IUCN & Source & Record time/ location \\
\hline Phylloscopus tenellipes & $\mathrm{P}$ & $\mathrm{P}$ & $\mathrm{P}$ & $\mathrm{LC}$ & Liu, unpublished & 2013-10-04/Wucheng \\
Phylloscopus reguloides & $\mathrm{W}, \mathrm{P}$ & $\mathrm{W}$ & & LC & CBRC & 2015-4-25/Baziqiang \\
Phylloscopus ricketti & $\mathrm{S}$ & $\mathrm{W}$ & & LC & CBRC & 2015-4-25/Baziqiang \\
Seicercus burkii & $\mathrm{R}$ & $\mathrm{W}$ & & LC & Birdbanding & 2014-4/13/Wucheng \\
Seicercus castaniceps & $\mathrm{W}$ & $\mathrm{W}$ & LC & Liu, unpublished \\
Zosterops erythropleurus & $\mathrm{P}$ & $\mathrm{P}$ & & LC & Liu, unpublished \\
Parus monticolus & $\mathrm{R}$ & $\mathrm{W}$ & LC & CBRC & 2002-12-29/Wucheng \\
Melophus lathami & $\mathrm{R}$ & $\mathrm{W}$ & LC & Liu, unpublished & \\
Emberiza godlewskii & $\mathrm{V}$ & $\mathrm{P}$ & & LC & CBRC & 2002-12-29/Wucheng \\
\hline
\end{tabular}

R/S/W/P: see Zheng (2011); distribution type: see Zheng (2011); Fauna: P- Palearctic realm, O- Oriental realm, W-wide species; Protection level: I- grade I of national protected animals; II-grade II of national protected animals; P-provincial key protected animals; IUCN: see the IUCN red list of threatened species; Source: CBRC-China BirdReport Center, the reference Liu, unpublished is provided by staff Yunzhen Liu at PLNNR. The reference Howes et al. (1988) was internal materials prepared by Howes J, Phin HK and Melville D, and they held Ornithological training course Poyang Hu, Jiangxi Province, People's Republic of China in 1988. Seicercus burkii was identified as follows MacKinnon et al. (2000).

Table II.- Checklist of debatable birds at Poyang Lake National Nature Reserve.

\begin{tabular}{llll}
\hline Scientific name & Data source & Results of action & Reason \\
\hline Circus aeruginosus & Ministry of Forestry, PR China & Deleted & Lacks distribution evidence \\
Charadrius hiaticula & Wu et al., 2000 & Deleted & Misidentification \\
Glaucidium passerinum & Wu et al., 2002 & Deleted & Misidentification \\
Lanius collurioides & Wu et al., 2002 & Deleted & Misidentification \\
Saxicola insignis & Ying et al., 2014 & Deleted & Misidentification \\
Emberiza calandra & Wu et al., 2002 & Deleted & Lacks distribution evidence \\
\hline
\end{tabular}

\section{RESULTS}

Species diversity

Up to March 31, 2017, fifty-seven (57) new species (Table I) were recorded based on the previous report of 330 bird species (Zeng et al., 2016b). Twenty-six recorded species originated from the website of China Bird Report Center (CBRC), thirty species were included based on unpublished internal materials, and one species was reported by bird banding. Six species (Charadrius hiaticula, Circus aeruginosus, Glaucidium passerinum, Emberiza calandra, Lanius collurioides and Saxicola insignis) (Table II) were deleted from the previous species checklist (Zeng et al., 2016b) because of absence of distribution evidence or species misidentification. Two species (C. aeruginosus and E. calandra) were not recorded in Jiangxi (MacKinnon et al., 2000; Zheng, 2011) while confirming with the authors who recorded four species (C. hiaticula, G. passerinum, L. collurioides and $S$. insignis) in PLNNR (Wu and Ji, 2002; Ying et al., 2014), we considered the four species misidentified due to similar morphological features of related species. Therefore, a total of 381 species (belonging to 18 orders, 64 families and 190 genera) were recorded (Supplementary Table I).
Table III.- Bird species composition of Poyang Lake National Nature Reserve.

\begin{tabular}{lcc}
\hline Order & Family (\%) & Species $\mathbf{( \% )}$ \\
\hline Podicipediformes & 2 & 0.8 \\
Pelecaniformes & 3 & 0.5 \\
Ciconiiformes & 5 & 5.0 \\
Phoenicopteriformes & 2 & 0.3 \\
Anseriformes & 2 & 9.7 \\
Falconiformes & 5 & 8.4 \\
Galliformes & 2 & 1.6 \\
Gruiformes & 6 & 5.0 \\
Charadriiformes & 13 & 16.0 \\
Columbiformes & 2 & 1.0 \\
Cuculiformes & 2 & 1.8 \\
Strigiformes & 3 & 2.1 \\
Caprimulgiformes & 2 & 0.3 \\
Apodiformes & 2 & 0.8 \\
Coraciiformes & 5 & 1.8 \\
Upupiformes & 2 & 0.3 \\
Piciformes & 2 & 1.3 \\
Passeriformes & 45 & 43.3 \\
Count & 100.0 & 100.0 \\
\hline
\end{tabular}


Table IV.- Indices of bird species diversities at different National Nature Reserves, Jiangxi Province.

\begin{tabular}{llccccccc}
\hline Name of Nature Reserves & Area (ha) & Orders & Families & Genera & Species & G-index & F-index & G-F index \\
\hline Poyang Lake & 22400 & 18 & 64 & 190 & 381 & 4.92 & 38.63 & 0.87 \\
Lushan & 29234 & 16 & 48 & 137 & 235 & 4.71 & 32.43 & 0.86 \\
Taohongling & 12500 & 16 & 44 & 108 & 170 & 4.65 & 25.31 & 0.82 \\
Nanjishan & 33300 & 15 & 52 & 121 & 215 & 4.49 & 27.02 & 0.83 \\
Jiulingshan & 11541 & 18 & 53 & 135 & 207 & 4.72 & 30.51 & 0.85 \\
Guanshan & 11500.5 & 17 & 53 & 124 & 182 & 4.68 & 26.07 & 0.82 \\
Wuyuan & 12992.7 & 17 & 65 & 177 & 306 & 4.75 & 36.89 & 0.87 \\
Tongboshan & 10800 & 17 & 49 & 129 & 199 & 4.65 & 29.91 & 0.84 \\
Wuyishan & 16007 & 17 & 52 & 152 & 260 & 4.74 & 34.08 & 0.86 \\
Yangjifeng & 10946 & 17 & 47 & 125 & 178 & 4.69 & 30.08 & 0.84 \\
Jinggangshan & 17217 & 17 & 56 & 170 & 296 & 4.9 & 35.53 & 0.86 \\
Qiyunshan & 17105 & 17 & 55 & 150 & 249 & 4.78 & 30.38 & 0.84 \\
Jiulianshan & 13411.6 & 17 & 56 & 170 & 263 & 4.94 & 36.38 & 0.86 \\
\hline
\end{tabular}

Non-passerine and passerine species numbered 261 (35 families) and 165 (29 families) which account for $56.7 \%$, and $43.3 \%$ respectively of total bird species in the protected area (Table III). The proportion of non-passerine birds is higher than that of passerines (Table III). Of 381 bird species 104 are resident (27.3\%), 97 summer visitor (25.5\%), 26 passage migrant (6.8\%), 147 winter visitor $(35.6 \%)$ and seven stragglers $(1.7 \%)$. The breeding birds account for $52.8 \%$, which is similar to proportion of breeding birds (51.3\%) at Jiangxi (Shao et al., 2010). The indices of G, F and G-F for the protected area are 4.922, 38.629 and 0.873 , respectively. These indices are higher than corresponding values for protected areas in Jiangxi (Table IV) to the exclusion of Wuyuan nature reserve at the family level (Huang et al., 2016).

\section{Fauna analyses}

Fauna analyses show that 205 species $(53.8 \%)$ belong to the Palearctic realm, 83 species $(21.8 \%)$ to Oriental realm and 93 species (24.4\%) are cosmopolitan. Thus the Palearctic species are dominant, followed by cosmopolitan species. Of 205 Palearctic species, 123 species are winter migrants, which account for $60 \%$ of Palearctic species. Among 201 breeding bird species 53 (26.4\%) were Palearctic, $78(38.8 \%)$ Oriental and $70(34.8 \%)$ were cosmopolitan.

\section{Rare and endangered species}

In the newly recorded species, thirteen species are classified as national protected wild animals of China (Table I). As of rare and endangered species in PLNNR, ten species (Aquila chrysaetos, Aquila heliaca, Ciconia nigra, G. leucogeranus, Grus monacha, Grus japonensis, Haliaeetus albicilla, Larus relictus, Mergus squamatus and Otis tarda) are listed as grade I nationally protected wild animals. Fifty-six species are protected as grade II nationally protect wild birds (Supplementary Table I). Four species (Bambusicola thoracicus, Garrulax poecilorhynchus, Parus venustulus and Turdus mupinensis) are endemic to China. Fifty-nine species are listed in the CITES appendices; ten (A. heliaca, C. boyciana, Falco peregrinus, G. leucogeranus, Grus japonensis, G. monacha, G. vipio, H. albicilla, Larus relictus and Pelecanus crispus) in CITES Appendix I and 49 in CITES Appendix II (Supplementary Table I). Two species (Aythya baeri and Grus leucogeranus) are critically endangered (CR), six species (Ciconia boyciana, G. japonensis, Platalea minor, Numenius madagascariensis, Mergus squamatus and Emberiza aureola) endangered (EN) and 16 are vulnerable (VU) (Supplementary Table I).

\section{Water bird fauna}

A total of 141 species of water birds were recorded, which account for $37.0 \%$ of all bird species. Of these, Palearctic species $(72.3 \%)$ dominate, followed by cosmopolitan (24.1\%) and Oriental species (3.6\%). Of 141 water birds, 92 species are wintering birds $(65.3 \%)$, followed by summer visitors $(17.0 \%)$ and residents $(8.5 \%)$. Thus, wintering birds shape the main part of water birds.

\section{DISCUSSION}

Species diversity

The diversity of birds is regarded as an indicator of regional ecological quality. In the present study, 57 new species were recorded. A total of 381 species were recorded, which account for $89.4 \%$ of total species in Poyang Lake (Zeng et al., 2016a), and $27.9 \%$ of national 
bird species (Zheng, 2011). The diversity of birds in PLNNR is fairly high. High species diversity might be related to unique hydrological conditions, and diversified habitats with grass lands, sparse grass lands or mudflat, and water lowlands in the PLNNR. The ten years monitoring data (1999-2008) show that the population of wintering waterfowl at PLNNR makes up about $50 \%$ of the whole Poyang Lake bird. Compared with other national nature reserves within Jiangxi province, the area size of PLNNR is not the largest (Table IV), but species diversities (e.g. species number, F-index and G-F index) are the highest, that highlights the importance of PLNNR for migratory birds.

\section{Fauna analyses}

The proportion of birds of Palearctic species is high. It also indicates that overwintering migratory birds are the main component in Palearctic birds. The results are in consonance with characteristics of its location, providing stopover/staging sites for overwintering birds (Shao et al., 2013). However, as of breeding birds, the Oriental realm species are dominant. The results are in accordance with avifauna of Poyang Lake, which belongs to Oriental realm. The inconsistent results may be caused by the seasonal movement of passage migrants, which is similar to Jiangxi avifauna (Tu et al., 2016).

\section{Suggestions}

High diversity of rare and endangered species was observed in PLNNR. In order to strengthen the protection of rare and endangered species, following suggestions are made: 1) periodically monitor rare and endangered species, especially two Critically Endangered species and six Endangered species to record their population, distribution and dynamics; 2) establish more protection monitoring stations to strengthen the monitoring abilities and meet the food demand of water birds in winter.

\section{ACKNOWLEDGEMENTS}

This research was funded by the Environment Monitoring System Key Station (Poyang Lake) of the Three Gorges Project (2016025) and the Jiangxi Province Major Disciplines Academic Leaders (20153BCB22007). We acknowledge reviewers' suggestive comments and special thanks to Dr. Ting Huang at Sichuan University for editing English.

\section{Supplementary material}

There is supplementary material associated with this article. Access the material online at: http://dx.doi. org/10.17582/journal.pjz/2018.50.4.1285.1291

\section{Statement of conflict of interest}

The authors report no conflicts of interest. The authors alone are responsible for the content and writing of the paper.

\section{REFERENCES}

Chen, B., Cui, P., Liu, G.H., Li, F.S., Wu, X.D., Wu, J.D., Zeng, N.J., Zhao, N. and Xu H.G., 2014. Relationships between changing water levels and numbers of wintering tuber-eating birds in Poyang Lake National Nature Reserve. J. Lake Sci., 26: 243-252. https://doi.org/10.18307/2014.0211

Chen, S.H., Huang, Q., Fan, Z.Y., Chen, C.S. and Lu, Y.W., 2012. The update of Zhejiang bird checklist. Chinese Birds, 3: 118-136. https://doi.org/10.5122/ cbirds.2012.0017

Hang, F.L. and Chang, J.C., 1997. A handbook of names of the birds in China. China Forestry Publishing House, Beijing.

Hu, Z.P., Ge, G. and Liu C.L., 2014. Response of wintering migratory birds to hydrological processes in Poyang lake. J. Nat. Resourc., 29: 1170-1179.

Huang, H.Q., Shi, J.Z., Sun, Z.Y., Zhang, W.W. and Qing, Y., 2016. Sichuan J. Zool., 35: 781-788.

Ji, W.T., Wu, J.D., Yi, W.S., Li, Z.W. and Mark, B., 2001. Survey report of Wading birds in National Poyang Lake Natural Reserve. Jiangxi Forest. Sci. Technol., 2: 29-31.

Jiang, Z.G., and Ji, L.Q., 1999. Avian-mammalian species diversity in nine representative sites in China. Chinese Biodiv., 7: 220-225.

MacKinnon, J., Phillipps, K. and He, F.Q., 2000. A field guide to the birds of China. Hunan Education Press, Changsha, Hunan.

Ministry of Forestry, People's Republic of China, and WWF-World Wide Fund for Nature, 1993. Management plan Jiangxi Poyang Lake National Nature Reserve. China Forestry Publishing House, Beijing.

Shan, J.H., 2013. The bird species diversity, population dynamics of endangered birds and conservation gap. Northeast Forestry University, Haerbin.

Shao, M.Q., Zhang, X.R., Yi, Z.L., Zeng, W.J., Zhai, B., Jian, M.F. and Tu, Y.L., 2010. Analysis on the bird diversity and avifauna in Jiangxi Province. Resourc. Environ. Yangtze Basin, S1: 128-131.

Shao, M.Q., Zeng, B.B., Xu, X.Z., Shang, X.L. and Dai, N.H., 2013. Preliminary study on bird composition and diversity in Poyang Lake watershed during non-breeding period. Acta Ecol. Sin., 33: 140-149. https://doi.org/10.5846/stxb201111061678 
Tu, F.Y., Han, W.J., Sun, Z.Y., Liu, X.H., Huang, X.F. and Huang, T., 2016. An updated checklist of the birds of Jiangxi, China. Agric. Sci. Technol., 17: 1183-1199.

Wu, J.D., Zhao, J.S. and Hong, Y.H., 2000. Breeding waterbirds of Poyang lake. Chinese J. Wildl., 21: 34-35.

Wu, Y.H. and Ji, W.T., 2002. Study on Jiangxi Poyang Lake natural nature reserve. China Forestry Publishing House, Beijing, pp. 217-227.

Ying, Q., Sun, Z.Y., Zhang, W.W., Huang, H.Q., Shi, J.Z. and Jia, W.M., 2014. An analysis of the bird community structure and diversity of birds in Wucheng Peninsula Poyang Lake, China. Acta
Agric. Univ. Jiangxiensis, 36: 199-208.

Zheng, G.M., 2011. A checklist on the classification and distributions of China. Science Press, Beijing.

Zeng, N.J., Zhu, Q., Tu, X.B., Liu, G.H., Yu, D.K., and Qian, F.W., 2016a. Exploring Bird Species in Poyang lake. Wetland Sci. Manage., 12: 56-64.

Zeng, N.J., Liu, G.H., Yu, D.K., Zhang, W.W., Wu, J.D. and Jin, J.F., 2016b. Analysis on the Number of Bird Species in Poyang Lake National Nature Reserve. Sichuan J. Zool., 35: 765-773.

Zhu, Q., Liu, G.H., Zeng, N.J., Wu, J.D., Jin, J.F., and Zhan, H.Y., 2012. Number and distribution of water birds wintered during 2007 to 2009 . Wetland Sci. Manage., 8: 52-56. 